\title{
KESESUAIAN LAHAN UNTUK SISTEM AGROFORESTRY DI KABUPATEN PURWOREJO BERDASARKAN POTENSI PERTANIAN SETEMPAT
}

\section{Ary Widiyanto dan Suhartono}

Balai Penelitian dan Pengembangan Teknologi Agroforestry,

Jl Raya Ciamis-Banjar Km 4, PO BOX 5 Ciamis

Email: ary_301080@yahoo.co.id

\begin{abstract}
ABSTRAK
Sektor pertanian berkontribusi sekitar 31\% pada pendapatan domestik regional bruto (PDRB) Kabupaten Purworejo. Meskipun demikian, pada beberapa tahun terakhir terjadi alih guna lahan pertanian menjadi non-pertanian. Salah satu cara untuk mengatasi hal tersebut yaitu dengan ekstensifikasi lahan pertanian di lahan hutan atau disebut agroforestry. Penelitian ini bertujuan untuk mengkaji kesesuaian lahan untuk agroforestry dengan mempertimbangkan potensi pertanian dan produk unggulan setempat. Metode yang digunakan adalah dengan pengecekan lokasi (ground check) dan menggunakan Sistem Informasi Geografis menggunakan software Arc GIS. Hasil penelitian menunjukan, di kabupaten Purworejo, sekitar 7.731 ha atau 7,47\% termasuk kategori sesuai dan sekitar 5.715 atau 5,56\% termasuk kategori sedang untuk pengembangan agroforestry. Lokasi terluas untuk pengembangan agroforestry adalah di Kecamatan Kemiri dengan area seluas 2.578 ha. Produk pertanian unggulan setempat yang direkomendasikan adalah kambing etawa (PE) dalam pola agrosilvopasture, tanaman penghasil obat (temulawak, kajibeling, lempuyang) dibawah tegakan pinus dalam pola silvofarmaka, dan papaya, manggis, dan durian dikombinasikan kayu sengon (Paraserianthes falcataria) dalam pola agrosilvikultur.
\end{abstract}

Kata kunci: Agroforestry, kesesuaian lahan, potensi pertanian, produk unggulan

\begin{abstract}
Agricultural sector contributed about 31\% to Purworejo Regency's Gross Regional Domestic Product (GRDP). Nevertheless, there were many land uses changing from agriculture to nonagriculture in recent years. One solution to overcome this problem is agriculture extensification in forest land, or known by agroforestry system. This research aimed to study land suitability for agroforestry system by considering local agricultural potensial and superior. The methods used are ground check and by using Geographical Information System with Arc GIS software. The results show that, in Purworejo Regency, about 7.731 ha or 7,47\% of area is categorized as suitable and about 5.715 or 5,56\% is categorized as medium for agroforestry system. The largest area for agroforestry development is Kemiri sub district with total area 2.578 ha. Local agricultural products recommendation is etawa goat (PE) in agrosilvopasture pattern, medicinal plants (temulawak, kajibeling, lempuyang) under pine tree in silvofarmaka pattern, and papaya, mangosteen, and durian combine with sengon (Paraserianthes falcataria) in agrosilvikultur pattern.
\end{abstract}

Keywords: Agroforestry, land suitability, agricultural potential, superior products 


\section{PENDAHULUAN}

Purworejo merupakan salah satu kabupaten di Jawa Tengah yang sangat bergantung pada sektor pertanian sebagai kontributor utama ekonomi daerah. Sektor pertanian berkontribusi sekitar $31 \%$ pada pendapatan domestik regional bruto (PDRB) Purworejo (BPS, 2012-2014a). Manajemen pengembangan sumberdaya alam melalui revitalisasi sektor pertanian, kehutanan, perkebunan dan perikanan serta peternakan ditujukan untuk meningkatkan kesejahteraan petani (Pemkab Purworejo, 2011).

Hal tersebut dapat dilakukan melalui praktek usaha pertanian yang baik, pengembangan usaha baru dan multi produk, pengembangan agroindustri pedesaan, pengembangan infrastruktur, pengembangan kelembagaan usaha petani, petani hutan, petani ikan dan petani ternak, serta peningkatan akses terhadap berbagai layanan usaha. Termasuk di dalamnya pengurangan hingga penghilangan berbagai hambatan usaha dan sumber ekonomi serta biaya tinggi. Pelestarian sumber daya alam dan lingkungan hidup secara berkelanjutan dapat dilakukan melalui pengelolaan pertanahan dan tata ruang, sehingga mendorong pengembangan usaha, penerapan teknologi dan kelembagaan yang ramah lingkungan (Bappeda Kabupaten Purworejo, 2011)

Tantangan terbesar yang di hadapi adalah bertambahnya penduduk yang tidak diimbangi dengan bertambahnya lahan pertanian. Jumlah lahan pertanian cenderung turun dari tahun ke tahun. Untuk mengatasi hal tersebut, salah satunya adalah dengan penambahan lahan pertanian, atau ekstensifikasi. Salah satu ekstensifikasi yang paling memungkinkan adalah penambahan lahan pertanian di dalam kawasan hutan, atau dikenal dengan istilah agroforestry.

Alih-guna lahan hutan menjadi lahan pertanian disadari menimbulkan banyak masalah seperti penurunan kesuburan tanah, erosi, kepunahan flora dan fauna, banjir, kekeringan dan bahkan perubahan lingkungan global. Agroforestri adalah salah satu sistem pengelolaan lahan yang mungkin dapat ditawarkan untuk mengatasi masalah yang timbul akibat adanya alih-guna lahan tersebut di atas dan sekaligus juga untuk mengatasi masalah pangan (Hairiah et al, 2003).
Tulisan ini bertujuan untuk mengkaji kesesuaian lahan untuk system agroforestry di Kabupaten Purworejo. Diharapkan dengan adanya informasi ini dapat dijadikan sebagai salah satu acuan dalam perluasan lahan pertanian dengan pengembangan produkproduk pertanian unggulan setempat.

\section{METODE PENELITIAN}

Penelitian ini dilaksanakan di Kabupaten Purworejo, Provinsi Jawa Tengah. Tahapan kegiatan penelitian dibedakan menjadi dua, yaitu 1) tahapan inventarisasi dan penilaian kondisi tata ruang eksisting, 2) penentuan klasifikasi kesesuian lahan lanskap agroforestry.

1) Inventarisasi dan penilaian kondisi tata ruang eksisting. Pada tahapan inventarisasi melakukan pengumpulan data primer dan sekunder untuk mendapatkan kondisi biofisik lokasi penelitian. Penentuan daerah (sampel pewakil) ditetapkan dengan sengaja (purposive sampling) menggunakan pendekatan unit lahan. Unit lahan terbentuk dari parameter penggunaan lahan dan jenis tanah.

2) Penilaian dan penentuan klasifikasi kesesuaian lahan agroforestry. Penilaian kesesuaian lahan lanskap agroforestry hanya dilakukan pada penggunaan lahan yang masuk kriteria kawasan budidaya menurut RTRW kabupaten. Penilaian kesesuaian lahan lanskap agroforestry menggunakan modifikasi kriteria dan indikator klasifikasi keseuaian lahan untuk sistem agroforostri yang diterapkan di DAS Khlong phu-khlong pook (Arifin, et. al., 2009). Penilaian kondisi penggunaan lahan eksisting dengan mencocokan kesesuian penggunaan lahan dengan skenario tata ruang yang ditetapkan masing-masing instansi terkait dengan menggunakan tool SIG.

Untuk mengetahui tingkat kesesuian lahan untuk sistem agroforestry menggunakan indek kesesuian lahan. Nilai indeks diperoleh dari overlay (tumpang susun) masing-masin peta tematik hasil pensekoran menurut Tabel 1. Tabel 2 menunjukkan Indek kesesuaian lahan untuk sistem agroforestry. 
Tabel 1.

Kriteria dan Indikator Penentuan Klasifikasi Kesesuian Lahan untuk Sistem Agroforestry

\begin{tabular}{llll}
\hline Indikator & Besaran & Kategori & Skor \\
\hline a. Lereng (\%) & $>35$ & Tinggi & 5 \\
& $26-35$ & Agak tinggi & 4 \\
& $16-25$ & Sedang & 3 \\
& $5-15$ & Agak rendah & 2 \\
& $<5$ & rendah & 1 \\
b. Persentase & $>80$ & Tinggi & 5 \\
elevasi (\%) & $80-60$ & Agak tinggi & 4 \\
& $60-40$ & Sedang & 3 \\
& $20-40$ & Agak rendah & 2 \\
& $<20$ & rendah & 1 \\
c. Jarak dari & $>2$ & Tinggi & 5 \\
sungai (km) & $1,6-2$ & Agak tinggi & 4 \\
& $1,1-1.5$ & Sedang & 3 \\
& $0,5-1$ & Agak rendah & 2 \\
& $<0,5$ & rendah & 1 \\
\hline
\end{tabular}

Keterangan : Prosentase elevasi $=$ (elevasi daerah setempat/elevasi tertinggi) x100\%

Tabel 2.

Indeks Kesesuaian Lahan untuk Sistem Agroforestry

\begin{tabular}{lll}
\hline Kelas & Indeks & Kriteria \\
\hline 1 & $>3$ & Sesuai \\
2 & $2,1-3$ & Sedang \\
3 & $<2$ & Tidak sesuai \\
\hline
\end{tabular}

\section{3) Analisis Data}

Pengolahan dan analisis data pada penelitian ini dilakukan secara statistik, baik secara deskriptif (kualitatif) maupun kuntitatif menggunakan perangkat komputer. Analisis kualitatif dilakukan tehadap struktur penggunaan lahan (khususnya agroforestri). Sedangkan variabel biofisik lahan dan sifat tanah dianalisa secara kuantitatif.

\section{HASIL DAN PEMBAHASAN}

Penggunaan lahan terbesar di Kabupaten Purworejo didominasi oleh kebun (30\% dari total luas wilayah) dan sawah $(29,2 \%)$. Sedangkan luas lahan hutan yang terdapat pada Kabupaten Purworejo sekitar 11\% yang terdiri dari hutan negara (produksi dan produksi terbatas) sebesar $6,6 \%$, dan hutan rakyat sebesar $4,4 \%$.

Pada penelitian ini lokasi penelitian lebih diarahkan pada sistem agroforestry yang terdapat pada penutupan lahan hutan rakyat, tegal/kebun, dan ladang. Berdasarkan observasi lapangan, diketahui bahwa praktek agroforestri sudah diterapkan oleh masyarakat di Kabupaten Purworejo. Agroforestri yang dipraktekan umumnya berupa agroforestri kompleks (complex agroforestry), yaitu kombinasi antara lebih dari satu pohon dengan lebih dari tanaman tahunan atau tanaman sela. Beberapa jenis pohon yang biasa ditanam antara lain jati, sengon, dan mahoni. Sementara itu, tanaman sela yang ditanam antara lain: tanaman bumbu, pisang, papaya, singkong dan buah-buahan.

Hasil survey lapangan menunjukan bahwa praktek agroforestry sederhana juga sudah dipraktekan di Kabupaten Purworejo, Hanya saja jumlahnya masih sedikit dibandingkan agroforestri kompleks. Salah satu praktek agroforestri dalam skala luas dilakukan oleh Perum Perhutani KPH Kedu Selatan yang menerapkan program Pengelolaan Hutan Bersama Masyarakat (PHBM) dengan pola tanama pinus-kapulaga dan beberapa tanaman sela lainnya.

Hasil penataan ruang kesesuaian lanskap agroforestry pada Kabupaten Purworejo secara spasial dapat dilihat pada Gambar 1. Hasil kajian diperoleh 3 kriteria kesesuaian lanskap agroforestry yaitu sesuai, sedang, dan tidak sesuai.

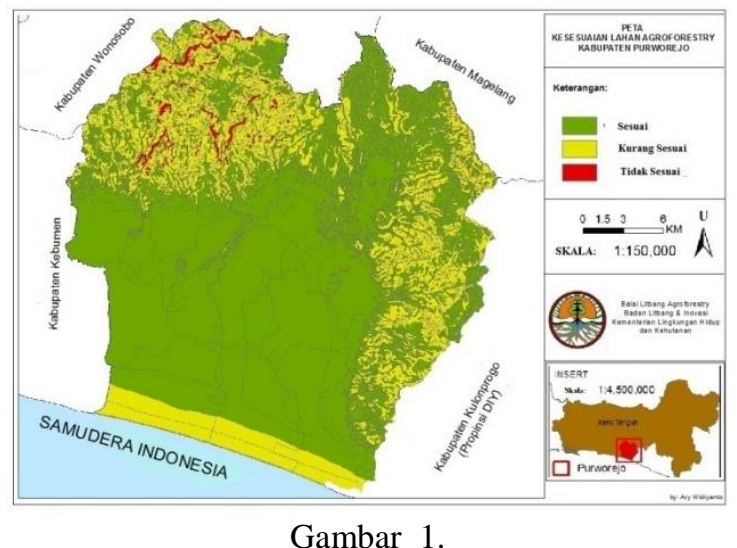

Peta sebaran spasial kesesuaian lahan agroforestry di Kabupaten Purworejo

Meskipun berdasarkan hasil analisa (Sekitar $53 \%$ ) dari luas tutupan lahan yang terdapat di Kabupaten Purworejo masuk dalam kriteria sesuai untuk diterapkan sistem agroforestry, namun mayoritas lahan tersebut termasuk penggunaan lahan pertanian monokultur. Purworejo bagian selatan memang memiliki lahan yang datar, sehingga banyak dimanfaatkan untuk pertanian semusim, seperti padi, kacang, jagung, dan 
kedelai. Sehingga, dalam analisa lanjutan difokuskan pada penggunaan lahan yang didominasi oleh tegakan kayu yaitu hutan produksi, hutan produksi terbatas, perkebunan, hutan rakyat, dan sebagian kecil kebun.

Berdasarkan hasil analisa, terdapat 3 penggunaan lahan yang sesuai untuk penerapan sistem agroforestry yaitu : hutan rakyat, perkebunan, dan hutan produksi (baik terbatas maupun tidak). Secara administrasi, peluang pengembangan agroforestry terbesar dapat dilakukan di Kecamatan Kemiri, dengan area masuk kategori sesuai seluas $2.578,27$ ha atau sekitar 33\% dari keseluruhan area kategori sesuai.

Penggunaan lahan hutan rakyat merupakan jumlah terbesar untuk pengembangan agroforestry (4.111 ha), disusul hutan produksi $(2.615,35 \mathrm{ha})$ dan terakhir perkebunan (1.005 ha). Untuk lebih jelas, dapat dilihat pada Gambar 2.

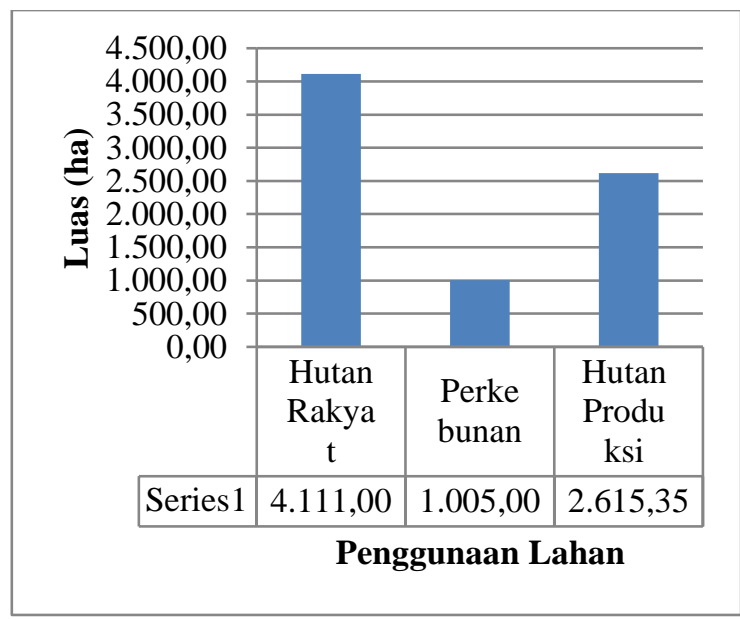

Gambar 2.

Grafik luas masing-masing penggunaan lahan yang sesuai diterapkan sistem agroforestry di Kabupaten Purworejo

Gambar 3 menunjukkan luasan masingmasing penggunaan lahan yang masuk kriteria sedang untuk diterapkan sistem agroforestry. Penggunaan lahan yang mempunyai luasan terbesar untuk diterapkan sistem agroforestry yang masuk kriteria sedang adalah hutan produksi (terbatas ataupun tidak).

Jumlah hutan rakyat di Kabupaten Purworejo adalah 9.742 ha. Produk kayu dari hutan rakyat yang paling banyak adalah kayu sengon (Paraserianthes falcataria) atau lebih dikenal oleh masyarakat Purworejo sebagai albasia. Pada tahun 2013, produksi kayu jenis

ini mencapai $44.806 \mathrm{~m}^{3}$. Selain itu, jenis kayu lain yang banyak dibudidayakan adalah mahoni, akasia, jati, dan sonokeling. Untuk kayu dari hutan produksi, yang dikelola oleh Perum Perhutani, diproduksi kayu jati dan pinus.

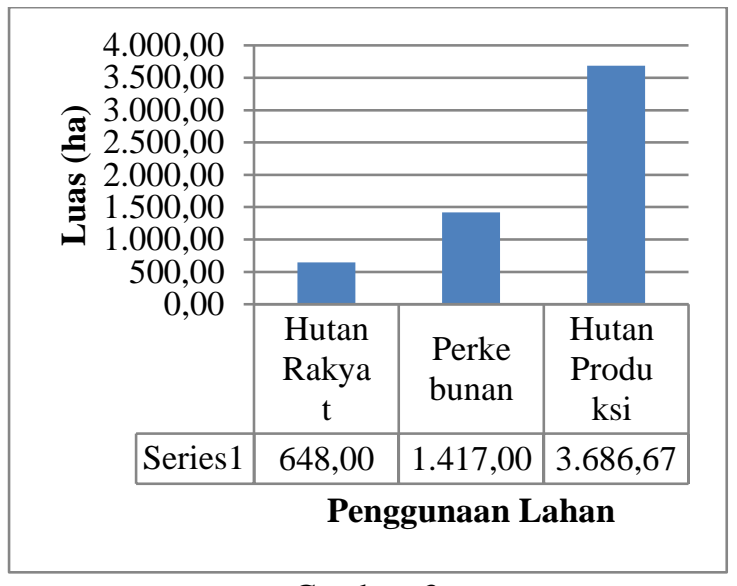

Gambar 3 .

Grafik luas masing-masing penggunaan lahan yang masuk kriteria sedang diterapkan sistem agroforestry di Kabupaten Purworejo

Produk-produk pertanian unggulan Kabupaten Purworejo yang memiliki daya saing regional (Propinsi) dan dapat dikembangkan dalam system agroforestry dapat dilihat pada Tabel 3 .

Tabel 3.

Produk-Produk Unggulan Daerah yang Berpotensi Dikembangkan dengan Sistem Agroforestry

\begin{tabular}{|c|c|c|c|}
\hline Produk & Kategori & $\begin{array}{l}\text { Produksi } \\
\text { Tengah }\end{array}$ & di Jawa \\
\hline & & Ranking & $\%$ \\
\hline Jeruk & Buah-buahan & 1 & 15 \\
\hline Pepaya & Buah-buahan & 1 & 12,3 \\
\hline Mangga & Buah-buahan & 1 & 55 \\
\hline Durian & Buah-buahan & 2 & 10 \\
\hline Kelapa & Buah-buahan & 2 & 13,7 \\
\hline Padi & $\begin{array}{l}\text { Tanaman } \\
\text { Pangan }\end{array}$ & $\begin{array}{l}\text { Surplus } 2 \\
\text { pada } 201\end{array}$ & $\begin{array}{l}40.000 \text { ton } \\
3\end{array}$ \\
\hline $\begin{array}{l}\text { Kambing } \\
\text { Etawa }\end{array}$ & Ternak & 1 & \\
\hline Temukunci & Tumbuhan Obat & 1 & 43,8 \\
\hline Temulawak & Tumbuhan Obat & 1 & 80 \\
\hline $\begin{array}{l}\text { Mahkota } \\
\text { Dewa }\end{array}$ & Tumbuhan Obat & 1 & 75,2 \\
\hline Produk & Kategori & $\begin{array}{l}\text { Produksi } \\
\text { Tengah } \\
\text { Ranking }\end{array}$ & $\begin{array}{l}\text { di Jawa } \\
\%\end{array}$ \\
\hline Lempuyang & Tumbuhan Obat & 2 & 29,7 \\
\hline Kajibeling & Tumbuhan Obat & 1 & 84,5 \\
\hline Temuireng & Tumbuhan Obat & 1 & 40,2 \\
\hline
\end{tabular}


Berdasarkan analisis kesesuaian tempat dikombinasikan dengan produk pertanian unggulan setempat, maka dapat direkomendasikan beberapa pola agroforestry yang sesuai. Produk pertanian dan pola agroforestry yang direkomendasikan antara lain kambing etawa (PE) dalam pola agrosilvopasture, tanaman penghasil obat (temulawak, kajibeling, lempuyang, dll) dibawah tegakan pinus dalam pola silvofarma, serta pepaya, manggis, dan durian dikombinasikan kayu sengon (Paraserianthes falcataria) dalam pola agrosilvikultur.

\section{KESIMPULAN DAN SARAN}

Kesimpulan. Hasil penelitian menunjukan bahwa sekitar 7.731 ha atau $7,47 \%$ dari luas kabupaten Purworejo termasuk kategori sesuai dan sekitar 5.715 atau 5,56\% dari luas kabupaten termasuk kategori sedang untuk pengembangan agroforestry. Lokasi terluas untuk pengembangan adalah di Kecamatan Kemiri dengan potensi seluas 2.578 ha. Produk pertanian unggulan setempat yang direkomendasikan adalah kambing etawa (PE) dalam pola agrosilvopasture, tanaman penghasil obat (temulawak, kajibeling, lempuyang) dibawah tegakan pinus dalam pola silvofarma, dan papaya, manggis, dan durian dikombinasikan kayu sengon (Paraserianthes falcataria) dalam pola agrosilvikultur.

Saran. Penentuan pola tata ruang lanskap agroforestry harus memperhatikan peruntukan rencana tata ruang secara umum. Selain itu, agroroforestry perlu didukung oleh input teknologi dan kearifan local, yaitu dengan selalu memperhatikan potensi setempat.

\section{DAFTAR PUSTAKA}

Arifin, H.S., Wulandari, C., Pramukanto, Q. dan Kaswanto, R.L. 2009. Analisis Lanskap Agroforestry; Konsep, Metode dan Pengelolaan Agroforestry; Skala lanskap dengan studi kasus Indonesia, Filipina, Laos, Thailand dan Vitnam. IPB Press. Bogor.

Bappeda \{Badan Perencanaan Pembangunan Daerah\} Kabupaten Purworejo. 2011. Rencana Tata Ruang Wilayah (RTRW) Kabupten Purworejo 2011-2031. Purworejo.

BPS \{Badan Pusat Statistik\}. 2012. Purworejo Dalam Angka 2011. Badan Pusat Statistik Kabupaten Purworejo. Purworejo.

BPS \{Badan Pusat Statistik\}. 2013. Purworejo Dalam Angka 2012. Badan Pusat Statistik Kabupaten Purworejo. Purworejo.

BPS \{Badan Pusat Statistik\}. 2014a. Purworejo Dalam Angka 2013. Badan Pusat Statistik Kabupaten Purworejo. Purworejo.

BPS \{Badan Pusat Statistik\}. 2014b. Jawa Tengah Dalam Angka. Badan Pusat Statistik Kabupaten Purworejo. Semarang.

Hairiah, K,. Sardjono, M.A. dan Sabarnurdin, S. 2003. Pengantar Agroforestri. World Agroforestry Center (ICRAF). Bogor.

Pemkab \{Pemerintah Kabupaten\} Purworejo. 2011. Rencana Pembangunan Jangka Menengah Daerah (RPJMD) Kabupaten Purworejo 2011-2015. Purworejo

Rauf, A. 2004. Agroforestri dan Mitigasi Perubahan Lingkungan. Maklah Falsafah Sains Sekolah Pasca Sarjana IPB. Bogor. 
Vol. 2, No. 2, Desember 2017: 291-357 AGRICORE-Jurnal Agribisnis dan Sosial Ekonomi Pertanian 